\title{
Suomen viljelymaiden pedologisia piirteitä ja maannoksia
}

\author{
Markku Yli-Halla ${ }^{1)}$, Delbert L. Mokma ${ }^{2)}$ ja Lawrence P. Wilding ${ }^{3)}$ \\ ${ }^{1)}$ MTT/Ympäristöntutkimus, 31600 JOKIOINEN, markku.yli-halla@mtt.fi \\ ${ }^{2)}$ Michigan State University, East Lansing, MI 48824, USA, mokma@ pilot.msu.edu \\ ${ }^{3)}$ Texas A\&M University, College Station, TX 77843, USA, wilding@tamu.edu
}

\section{Johdanto}

Meidän tulee kertoa tutkimustuloksista ja koeolosuhteista kulloisenkin yleisömme ymmärtämällä kielellä. Suomessa ja muissa Pohjoismaissa maata voi luonnehtia lajitekoostumuksen ja orgaanisen aineksen pitoisuuden perusteella. Tällä alueella on samanlaisen ilmaston ja geologisen historian takia yhteinen käsitys siitä, millaista on savimaa, millaista hieta tai multamaa. Mutta kun yleisönä on tämän alueen ulkopuolisia ihmisiä, maata luonnehditaan maannostumista kuvaavilla ilmaisuilla eli kertomalla maaprofiilissa tapahtuneiden prosessien tuloksena syntyneistä piirteistä; lajitekoostumus ja humuspitoisuus ovat täydentäviä tietoja. Myös kansainväliset maaperän luokittelujärjestelmät kuten amerikkalaisperäinen Soil Taxonomy (Soil Survey Staff 1999), FAOn/Unescon järjestelmä (FAO 1988) ja sen pohjalle rakennettu World Reference Base for Soil Resources (WRB) -järjestelmä (FAO 1998), jota Kansainvälinen Maaperätieteiden Seurojen Liitto (IUSS) suosittelee, perustuvat etupäässä maannostumisen tuloksena syntyneisiin ominaisuuksiin. Maannostumisilmiöiden havainnointi auttaa myös meitä itseämme ymmärtämään paremmin maidemme käyttäytymistä.

\section{Aineisto ja menetelmät}

Suomen viljelymaiden maannoksia on dokumentoitu melko vähän. Tätä tietoa on hankittu lisää tutkimalla vuodesta 1997 alkaen noin 40 suomalaista viljelymaaprofiilia (Mokma \& Yli-Halla 2000, Mokma et al. 2000, Yli-Halla et al. 2000, Yli-Halla \& Mokma 2001). Tässä kirjoituksessa kerrotaan viljelymaissamme esiintyvistä maannostumisilmiöistä pääasiassa Jokioisissa, Helsingissä ja Sotkamossa vuonna 2001 tutkittujen maaprofiilien tulosten perusteella. Maaprofiilit tutkittiin noin 1,5 metrin syvyyteen saakka. Niiden morfologia (lajitekoostumus, rakenne, värit, kovuus ym.) luonnehdittiin horisonteittain ja maanäytteistä tehtiin tavanomaisia maa-analyysejä. Maanäytteistä tehtiin myös ohutleikkeitä (30 um), joiden mikromorfologiaa tutkittiin petrografisella mikroskoopilla. Näiden havaintojen lisäksi esitetään viljelymaidemme yleisimmät FAOn ja WRB-luokituksen sekä Soil Taxonomy-järjestelmän mukaiset maannosnimet.

\section{Tulokset ja niiden tarkastelu \\ Savimaat}

Savimaidemme keskeiset maannostumisprosessit ovat mineraalien rapautuminen, rakenteen muodostuminen ja raudan hapettumis- ja pelkistymisreaktiot, joihin liittyy rautayhdisteiden liukeneminen ja saostuminen. Savimaissamme havaitaan myös alkavaa saveksen kulkeutumista (clay eluviation/ illuviation), jonka seurauksena huokosten ja halkeamien seinämiin varsinkin noin metrin syvyydessä kertyy ohut saveskerros.

Luonnontilainen uusi savisedimentti on siniharmaata rakenteetonta (massiivista) massaa, joka alkaa kuivuessaan halkeilla. Halkeilun seurauksena savimaaprofiiliin pääsee kesän sateettomina kausina ilmaa (happea), ja pelkistyneessä muodossa oleva rauta $\left(\mathrm{Fe}^{2+}\right)$ hapettuu ja saostuu ruskeina läiskinä tai yhtenäisenä kerroksena jankon ja pohjamaan kokkareiden pinnoille. Savimaiden harmaa perusväri kertoo pelkistyneistä oloista ja ruosteläiskät siitä, että maanesteeseen liuennut rauta on paikoitellen hapettunut ja saostunut. Syyssateiden alettua Jokioisilla tehdyissä kaivauksissa havaittiin, että pohjamaan kokkareiden pinnat ovat yhtenäisen harmaat kun taas prismojen sisäosat ovat ruskeammat ja rautasaostumien värjäämät. Tämä viittaa siihen, että ainakin tuohon aikaan vuotta kokkareiden sisäosissa on hapelliset olot, mutta kokkareiden välit ovat kyllästyneestä pintamaasta tulevan valunnan takia menneet anaerobiseen tilaan. Liejusavilla, joilla usein on korkea pohjavesi, pohjamaan kokkareet ovat sisältä harmaat (pelkistyneet) ja ulkopinnoiltaan ruskeammat (hapettuneet).

Harmaa väri, ruostesaostumat, veden vaivaamilla mailla yhtenäisen ruosteen peitossa olevat kokkareet ja vanhoihin juurikanaviin saostuneet rautapillit ovat savimaillemme tyypillisiä piirteitä. Englanninkieliset termit näille hapettavien ja pelkistävien olojen vuorottelua osoittaville merkeille ovat redoximorphic features (Soil Taxonomy) ja gleyic and stagnic properties (FAO, WRB). Meille 
humidin alueen asukkaille savien harmaus on itsestään selvyys, mutta lämpimämmässa ja kuivemmassa ilmastossa savet ovat ruskeita, tropiikissa jopa punaisia.

Ojitus on vaikuttanut ratkaisevasti savimaidemme kehitykseen, sillä tavanomainen salaojitus saa aikaan rakenteen muodostumista ainakin metrin syvyyteen saakka, eli paljon syvemmälle kuin luonnontilaisessa savimaassa todennäköisesti olisi tapahtunut. Jäykkiin savimaihimme muodostuu kuivumisen ja kutistumisen takia kestävä prismamainen rakenne yllättävän lyhyessä ajassa. Kyntämättä viljeltäessä maan pintakerros $(0-10 \mathrm{~cm})$ säilyy hienorakenteisena vuosittaisen matalan muokkauksen takia mutta tämän alapuolelle eli entisen muokkauskerroksen alaosaan kehittyy jo muutamassa vuodessa prismamainen rakenne. Voidaan olettaa, että siellä juurten kasvutila rajoittuu prismojen väleihin. Prismojen sisäosat saattavat lisäksi olla hapettomassa tilassa kauemmin kuin syvemmältä muokatuissa maissa, mikä voi heikentää juurten kasvua prismojen sisään. Hapettomuuden kehittymistä muokkauskerroksessa edistää siinä oleva mikrobeille kayttökelpoinen hiiliravinto. Ohutleikkeissä näkyy myös jankon tiiviys.

Pohjamaahan muodostuu karkeampi prismarakenne. Prismat voivat olla halkaisijaltaan parikymmentä senttiä ja niiden pituus voi olla puoli metriä. Prismojen väliset kuivumisen ja kutistumisen tuloksena syntyneet halkeamat ovat melko pysyviä, ja, kuten tunnettua, ne ovat madonreikien ja juurikanavien ohella tärkeitä veden kulkureittejä. Prismojen välissä on usein ohuempia kiilamaisia kokkareita (wedge-shaped aggregates). Pohjamaan kokkareiden pinnoilla on paljon pieniä kiiltäviä kohtia (pressure faces), jotka ovat syntyneet paisuvien savikokkareiden painautuessa toisiaan vasten. Savimaistamme ei ole löytynyt merkkiä siitä, että kokkareet olisivat varsinaisesti liukuneet toistensa sivuitse, jolloin syntyisi liukupintoja (slickensides). Niiden syntyminen edellyttäisi ilmeisesti kuivempaa ilmastoa ja maan ajoittaista perusteellisempaa kuivumista (ja kutistumista); maan ikä tai mineralogia eivät ole esteenä liukupintojen esiintymiselle suomalaisissa savimaissa.

Maan nuorta ikää ja/tai pedogeneesin vähäisyyttä osoittaa se, että varsinkin pohjamaassa prismat katkeilevat vaakasuoraan (platy structure) myötäillen niitä kerrosrajoja, jotka ovat muodostuneet sedimentin laskeutuessa jääkauden aikana ja sen jälkeen. Syvemmällä nämä kerrokset ovat usein silminkin havaittavissa, mutta jankosta ne ovat pedogeneesin seurauksena enimmäkseen hävinneet. Nämä kerrokset ovat selvästi nähtävissä noin 70 sentin syvyydestä otetuista näytteistä tehdyissä ohutleikkeissä.

\section{Hiesumaat}

Myös puhtaimmat hiesumaat ovat yleisväriltään vaaleanharmaita. Ne ovat tiiviitä, ja on mahdollista, että niissäkin harmaa väri littyy siihen, että rautaoksidit ovat liuenneet niistä pelkistyneissä oloissa, tai rautasaotumia ei niihin ole koskaan liiemmälti kehittynytkään. Tätä tulkintaa tukee se, että esimerkiksi Laukaalla jopa muokkauskerroksen alaosassa on pitkällisiä pelkistyneitä oloja osoittavia vaaleita soikeita halkaisijaltaan sentin-parin suuruisia laikkuja. Nämä ilmiöt havaittiin hiesumaassa, jonka sijainti ei viittaa korkean pohjaveden esiintymiseen kyseisellä paikalla.

\section{Hieta-, hiekka- ja moreenimaat}

Karkeimmat kivennäismaat ovat yleisväriltään ruskeita. Tämä johtuu siitä, että silikaattihiukkasten pinnoille on saostunut rautahydroksidiverho. Märissä maastonkohdissa sijaitsevien karkeidenkin kivennäismaiden pohjamaa voi olla harmaa. Karkeat hietamaat ovat usein voimakkaasti podsoloituneita. Näillä mailla voi muokkauskerroksen alta löytää valkean huuhtoutumiskerroksen ja sen alta tummanruskean rikastumiskerroksen, joka on joskus iskostunut rautapalsi (ortstein). Hienoilla hiedoilla ei juurikaan havaita podsoloitumista, ja moreeneillakin podsoloituminen on monesti heikkoa. Näillä molemmilla maalajeilla on enemmän helposti rapautuvia mineraaleja hidastamassa podsolimaan morfologian kehittymista. Kuivissa hiekkamaissa puolestaan ei välttämättä tapahdu näkyvää podsoloitumista sen takia, että niissä ei aina ole rautapitoisia mineraaleja.

\section{Rauta ja fosforilannoitustarve}

Karkeilla hietamailla voi usein havaita muokkauskerroksessa ruskeita podsoliprofiilin rikastumiskerroksesta peräisin olevia rautahydroksidi-iskostuman kappaleita, joita kyntö on nostanut muokkauskerrokseen. Podsoloituneiden maiden kyntö syvältä, niin että raudan saostumiskerros sekoittuu muokkauskerrokseen, johtaa suureen fosforilannoituksen tarpeeseen ja lannoituksen pieneen jälkivaikutukseen. Jokioisten savimaallakin näkyy ohutleikkeissä suuri määrä (10\% tilavuudesta) pieniä ( $<2 \mathrm{~mm})$ rautahydroksidihippuja. Rautahydroksidien runsaus on monesti nähtävissä paljain silminkin. Suomessa noudatettavat korkeahkot fosforilannoitussuositukset lienevät perusteltavissa suurella raudan määrällä. 


\section{Suomalaisten viljelymaiden maannosten nimet}

Savimaidemme nimi Soil Taxonomy-järjestelmässä on Vertic Cryaquept, joka painoittaa maiden halkeilevuutta (vertic), märkyyttä (-aqu-) ja sitä, että niissä on jankossa rapautumisen merkkejä ja rakenteen muodostumista (Inceptisol, -ept-pääte). Lisämääreenä voidaan antaa very fine (aitosavet) tai fine (muut savimaat). FAOn järjestelmän ja WRB:n mukainen nimi Vertic Cambisol puolestaan painottaa maiden halkeilua (vertic properties) ja ilmaisee siten välillisesti niiden olevan savimaita. Jotkut savimaamme, varsinkin liejusavet, saattavat olla niin märkiä ja pelkistyneitä, että ne täyttävät gley-maan vaatimukset ja ovat nimeltään Dystric Gleysol tai Vertic Gleysol.

Hiesut ja hienot hiedat saavat Soil Taxonomy -järjestelmässä yleisimmin nimen Oxyaquic Eutrocryept. Nimi ilmaisee sen, etta niissä on jankossa rakenne (Inceptisol, -ept-pääte) ja melko korkea emäskyllästysaste (Eutro-). Oxyaquic ilmaisee sen, että maat ovat aika ajoin märkiä mutta vähemmän pelkistyneitä kuin savimaiden nimessä oleva -aqu-tavu edellyttää. FAOn järjestelmän ja WRB-luokituksen mukainen nimi on useimmiten Eutric Cambisol, joka painottaa rakenteen muodostumista ja melko korkeaa emäskyllästysastetta. Näissä maissa on tosin usein niin heikosti kehittynyt rakenne, että jonkun mielestä niiden pitäisi paremminkin saada nimekseen Eutric Regosol.

Podsoloituneiden karkeiden hietojen ja hiekkojen nimi on tavallisesti Oxyaquic Haplocryod (Soil Taxonomy) tai Haplic Podzol (FAO ja WRB). Podsoloitumattomat karkeat hiedat ovat nimeltään Oxyaquic Cryorthent (Soil Taxonomy) tai jos ne ovat hyvin lajittunutta karkeaa hietaa tai hiekkaa vähintään metrin syvyyteen saakka, nimi on Oxyaquic Cryopsamment. Vastaavat FAOn ja WRBn nimet ovat Dystric Regosol ja Dystric/Spodic Arenosol. Viljellyt moreenit ovat tavallisesti Oxyaquic Cryorthent (Soil Taxonomy) tai Dystric Regosol (FAO, WRB), sillä ne eivät ole yleensä kovin voimakkaasti podsoloituneita.

Viljellyt turvemaat saavat nimekseen Typic Cryosaprist (Soil Taxonomy), Terric Histosol (FAO) tai Sapric Histosol (WRB). Multamaiden nimeäminen kansainvälisesti ymmärrettävällä tavalla on pulmallista, sillä Pohjoismaiden ulkopuolella sellaista maaluokkaa ei luokituksissa pääluokkana esiinny. Multamaat, joiden jankko on savea, lienevat yleisimmin Histic Cryaquept (Soil Taxonomy). Karkeammat multamaat, joiden humuspitoisuus on alle $30 \%$, ovat Typic Cryaquept (Soil Taxonomy), mikä nimi ilmaisee huonosti näiden maiden ominaisuuksia, ja multa- ja turvemaiden rajamailla olevat karkealle maalle kehittyneet multamaat ovat nimeltään Histic Cryaquept. FAO- järjestelmässä kaikista multamaista voinee käyttää nimeä Umbric Gleysol ja WRB-järjestelmässä nimeä Histic Gleysol (turvemaata lähestyvä multamaa) tai Umbric Gleysol (vähemmän humuspitoinen multamaa).

\section{Viljelymaamme ovat kylmiä}

Soil Taxonomy-järjestelmässä maan lämpotilaa käytetään yhtenä luokittelutekijänä. Suomalaisten maiden matala lämpötila ilmaistaan -cry-tavulla. Viljelymaamme kuuluvat Soil Taxonomyjärjestelmän kylmimpään lämpotilaluokkaan (cryic soil temperature regime; Yli-Halla \& Mokma 1999, Yli-Halla ym. 2001). Cryic-alueen eteläraja kulkee Suomenlahdessa ja Ruotsissa Uppsalan tienoilla. Tämä lämpötilaluokittelu voi olla argumentti neuvoteltaessa Suomen maataloudelle tukieuroja pysyvien luonnonhaittojen perusteella.

\section{Suomi kansainvälisillä maaperäkartoilla}

Monet kansainväliset maaperäkartat, joilla Suomi näkyy, perustuvat maannosluokitukseen. Niistä ajankohtaisin on EU:n komission alaisen Euroopan maaperätoimiston koordinoima Euroopan maaperäkartta eli Soil Geographic Database of Europe, 1:1000 000 (European Soil Bureau, 1998) ja siihen liittyvä maaprofiilitietokanta (Soil Profile Analytical Database). Kartan tarkempi versio (1:250 000) on valmisteilla. Olemassaoleva kartta ja tietokanta antavat perustietoa Suomen maape-rästä. Suomessa esiintyy sen mukaan seuraavia maannoksia: Haplic Podzol (podsolit, 55\% maa-alasta), Dystric ja Eutric Histosol (turvemaat, 29\%), Dystric ja Vertic Cambisol (tavanomaiset viljelymaat, 8\%), Dystric ja Vertic Gleysol (liejut ja liejuiset maat, 2\%), ja Haplic Leptosol (kalliomaa, 5\%). Tämä on ainoa valtakunnallinen maannosaineisto, joka Suomesta on olemassa. Käytännössä sama aineisto on sisällytetty aikanaan myös FAOn/Unescon Maailman maaperäkarttaan (FAO 1974), Pohjoismaiden maaperakarttaan (Rasmussen et al. 1990), lähinnä kanadalais-yhdysvaltalais-venäläisenä yhteistyönä toteutettuun Pohjoiskalotin maaperäkarttaan (Tarnocai et al. 2001) ja Maailman maaperäkartasta Soil Taxonomy-järjestelmän nimistön mukaan tehtyyn muunnokseen (Soil Survey Staff 1999). 


\section{Ydin}

Viljelymaidemme keskeisiä maannostumisprosesseja ovat mineraalien rapautuminen, rakenteen muodostuminen, raudan hapettumis- ja pelkistymisreaktiot ja saveksen kulkeutuminen maaprofiilissa alaspäin. Pelkistyneiden olojen aikaansaama harmaa väri, ruostesaostumat, veden vaivaamilla mailla yhtenäisen ruosteen peitossa olevat kokkareet ja vanhoihin juurikanaviin saostuneet rautapillit ovat savimaillemme tyypillisiä piirteitä. Ojitus on saanut aikaan rakenteen muodostumista ainakin metrin syvyyteen saakka. Maaperämme nuoruutta osoittaa se, että Jokioisten savimaassa on jäljellä sedimentin laskeutuessa syntynyt kerrosrakenne noin 70 sentin alapuolella. Hieta-, hiekka- ja moreenimaat ovat ilmavampia ja tavallisesti väriltään ruskeita, kun maahiukkasia peittää rautahydroksidiverho. Karkeat hietamaat ovat usein voimakkaasti podsoloituneita, mutta moreeneilla podsoloituminen on monesti heikkoa. Podsoloituneiden maiden kyntö syvältä, niin että raudan saostumiskerros sekoittuu muokkauskerrokseen, johtaa suureen fosforilannoituksen tarpeeseen ja lannoituksen pieneen jälkivaikutukseen. Kansainvälisten maannosluokitusjärjestelmien mukaiset nimet heijastelevat monipuolisesti Suomen maaperässä havaittuja maannostumisilmiöitä. Euroopan maaperäkartalla maaperäämme hallitsevat FAO:n luokituksen mukaan Podzol-, Histosol- Cambisol- ja Leptosol-maat.

\section{Kiitokset}

Tässä julkaisussa esitetyt tulokset on osittain aikaansaatu Agronomiliiton tiede- ja tutkimussäätiön myöntämän apurahan turvin.

\section{Kirjallisuusviitteet}

European Soil Bureau 1998. The Soil Geographic Database of Europe at Scale 1:1000 000.

FAO 1974. FAO - Unesco Soil Map of the World, 1:5000 000. Vol. 1, Legend. Unesco, Paris.

FAO 1988. FAO - Unesco Soil Map of the World. Revised legend with corrections. World Soil Resources Reports 60. FAO, Rome.Reprinted as Technical Paper 20, ISRIC, Wageningen, 1994.

FAO 1998. World reference base for soil resources. World Soil Resources Reports 84. FAO, Rome. 92 p.

Mokma, D.L. \& Yli-Halla, M. 2000. Keys to Soil Taxonomy for Finland. USDA - Natural Resources Conservation Service - National Soil Survey Center. 31 p.

-, Yli-Halla, M. \& Hartikainen, H. 2000. Soils in a young landscape on the coast of southern Finland. Agric. Food Sci. Finl. 9: 291-302.

Rasmussen, K., Sippola, J., Urvas, L., Låg, J., Troedsson, T. \& Wiberg, M. 1991. Soil map of Denmark, Finland, Norway and Sweden, scale 1:2000 000. Landbruksforlaget, Oslo.

Soil Survey Staff 1999. Soil Taxonomy. A basic system of soil classification for making and interpreting soil surveys. USDA - Natural Resources Conservation Service. Agriculture Handbook 436. $2^{\text {nd }}$ Ed. 869 p.

Tarnocai, C., Kimble, J., Swanson, D., Goryachkin, S., Naumov, Y. M., Stolbovoi, V., Jakobsen, B., Broll, G. , Montanarella, L. \& Arnoldussen, A. Aug. 2001. Northern Circumpolar Soil Map. Agriculture and AgriFood Canada.

Yli-Halla, M. \& Mokma, D.L. 1999. Soil temperature regimes in Finland. Agric. Food Sci. Finl. 7:507-513.

-\& Mokma, D.L., Peltovuori, T. \& Sippola, J. 2000. Suomalaisia maaprofiileja. Maatalouden tutkimuskeskuksen julkaisuja A 78. $104 \mathrm{p}$.

- \& Mokma, D.L. 2001. Soils in an agricultural landscape of Jokioinen, south-western Finland. Agric. Food Sci. Finl. 10: 33-43.

- Mokma, D.L. \& Starr, M. 2001. Criteria for cryic and frigid temperature regimes. Soil survey horizons 42: 11-18. 